\title{
Left atrial volume assessment by area-length method compared to multislice volumetric method using cardiovascular magnetic resonance imaging
}

\author{
Atif Bashir ${ }^{* *}$, Mark Rabbat ${ }^{2}$, Santanu Biswas ${ }^{2}$, David Wilber ${ }^{2}$, Thriveni Sanagala², Mushabbar A Syed ${ }^{2}$ \\ From 16th Annual SCMR Scientific Sessions \\ San Francisco, CA, USA. 31 January - 3 February 2013
}

\section{Background}

Left atrial (LA) size is a strong predictor of cardiovascular events in patients with atrial fibrillation (AF) and a variety of other cardiovascular diseases. Left atrial volume (LAV) measurement is the preferred method for assessment of LA size. The most widely used technique for LAV assessment is the area-length (AL) method using 2D echocardiography. Studies have shown that AL method by echocardiography significantly underestimates LAV when compared with CMR using multislice volumetric (MSV) method. However, MSV method is time consuming due to increased acquisition and analysis time. We sought to compare LAV assessment by CMR using the more rapid AL method with MSV method.

\section{Methods}

We prospectively studied 273 patients with AF who underwent CMR on a 3T scanner (Siemens Trio). Image acquisition included SSFP cine of LA in short axis-stack, horizontal long-axis (4 chamber) and vertical long-axis ( 2 chamber) views. LAV by AL method was measured on CMR long axis views in end-systole as recommended by the American Society of Echocardiography. LAV by MSV method was performed by tracing the LA endocardial border on LA short axis stack in a phase with largest LA dimension. LA appendage and pulmonary veins were excluded by both methods. LAV and LAV index measurements by AL and MSV methods were compared using Pearson's correlation, Regression analysis and Bland-Altman plots.

\section{Results}

CMR was successfully completed and analyzed in 252 patients; mean age $60.5 \pm 10.7$ years, 185 males (73.4\%). Paroxysmal AF was the most common arrhythmia (57.5\%). Mean $\mathrm{CHA}_{2} \mathrm{DS}_{2}$-VASc score was $1.7 \pm 1.3$. Coronary artery disease was present in $31(12.3 \%)$, hypertension $154(61.1 \%)$, heart failure 7 (2.8\%), diabetes mellitus 34 (13.5\%), TIA/CVA 18 (7.1\%) and peripheral vascular disease in $7(2.8 \%)$ patients.

Mean heart rate during CMR was $68.7 \pm 15.6$ beats/ min, $82 \%$ were in sinus rhythm. Mean left ventricular EF was $58.6 \pm 8.1 \%$ and right ventricular EF was $47 \pm 7.2 \%$.

Table 1 shows the mean LAV and LAV index by AL and MSV methods and their correlation. LAV and LAV index by the AL method was significantly higher compared to MSV method ( $p<0.001$ for both). AL method showed good correlation with MSV method. Bland-Altman plot showed mean measurement difference of $5.5 \pm 10.5 \mathrm{ml} / \mathrm{m}^{2}$ for LAV index between two methods. AL method tend to overestimate LAV index compared to MSV method by 26 $\mathrm{ml} / \mathrm{m}^{2}$ or underestimate by $14.9 \mathrm{ml} / \mathrm{m}^{2}$ (Figure 1 ).

\section{Conclusions}

LA volume measurements by CMR AL method correlate well with the MSV method but limits of agreement are wide. These differences should be taken into account when using AL method for clinical or research purposes.

\section{Funding}

None. 
Table 1

\begin{tabular}{ccc}
\hline & $\begin{array}{c}\text { LA volume } \\
(\mathrm{ml})\end{array}$ & $\begin{array}{c}\text { LA volume index } \\
\left(\mathrm{ml} / \mathrm{m}^{2}\right)\end{array}$ \\
\hline Area-length method & $123.4 \pm 43.5$ & $58.7 \pm 19.8$ \\
\hline $\begin{array}{c}\text { Multislice volumetric } \\
\text { method }\end{array}$ & $111.4 \pm 36.6$ & $53.1 \pm 16.2$ \\
\hline p-value & $<0.001$ & $<0.001$ \\
\hline Pearson correlation & 0.87 & 0.85 \\
\hline $\mathrm{R}^{2}$ & 0.76 & 0.71 \\
\hline
\end{tabular}

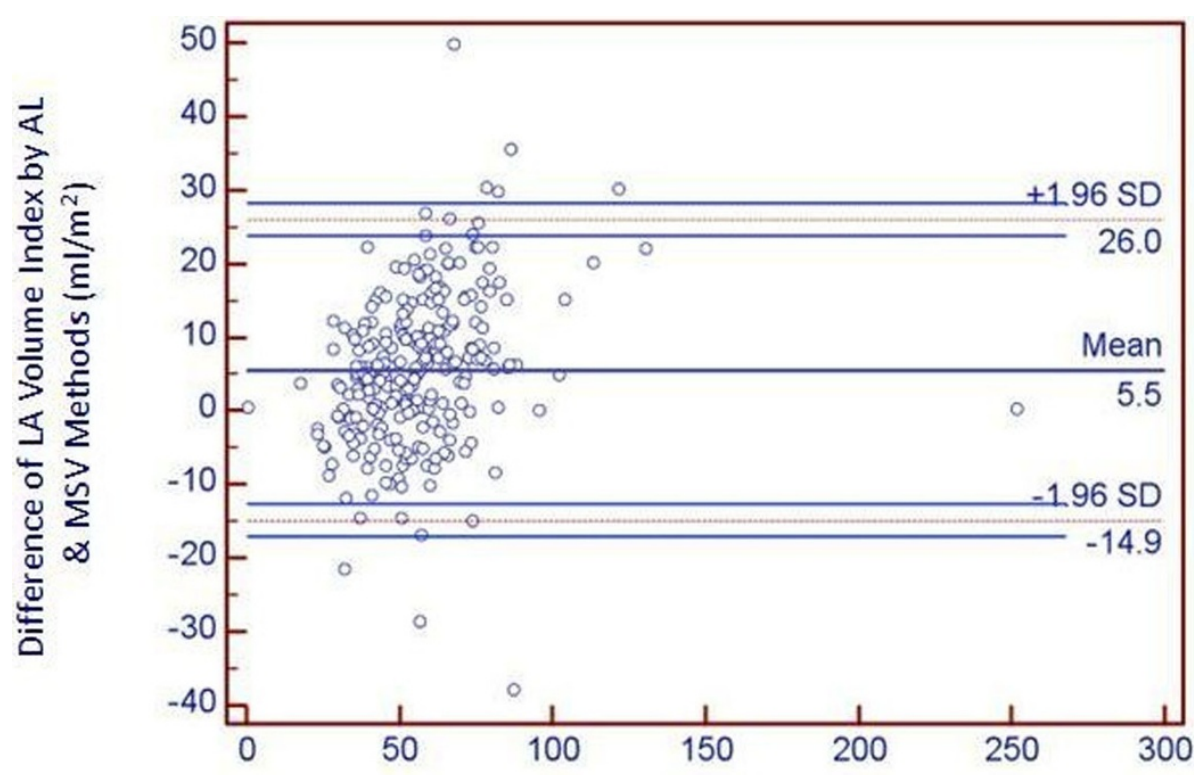

\section{Mean of LA Volume Index by AL \\ \& MSV Methods $\left(\mathrm{ml} / \mathrm{m}^{2}\right)$}

Figure 1 Bland-Altman plot of area-length vs. volumetric method

\section{Author details}

'Department of Medicine, Loyola University Medical Center, Maywood, IL, USA. ${ }^{2}$ Heart \& Vascular Institute, Loyola University Medical Center, Maywood, IL, USA.

Published: 30 January 2013

doi:10.1186/1532-429X-15-S1-E97

Cite this article as: Bashir et al: Left atrial volume assessment by arealength method compared to multislice volumetric method using cardiovascular magnetic resonance imaging. Journal of Cardiovascular Magnetic Resonance 2013 15(Suppl 1):E97.
Submit your next manuscript to BioMed Central and take full advantage of:

- Convenient online submission

- Thorough peer review

- No space constraints or color figure charges

- Immediate publication on acceptance

- Inclusion in PubMed, CAS, Scopus and Google Scholar

- Research which is freely available for redistribution

Submit your manuscript at www.biomedcentral.com/submit 